\title{
Rainfall-runoff co-relationship for lower mahi basin, India
}

\begin{abstract}
Rainfall-runoff co relationship can be carried out within a purely analytical framework based on observations of the inputs and outputs from a catchment area. In this study an attempt has been made to develop a similar co relationship for Lower Mahi Basin, situated in the Western Part of India. Rainfall data for the important rain gauging sites was considered for a period of 10 years. Runoff depth was calculated using the SCS-CN method. Utilizing both the parameters, a rainfall-runoff co relationship was obtained using the regression equation.
\end{abstract}

Keywords: rainfall-runoff, lower mahi basin, regression equation
Volume I Issue 5 - 2017

\author{
Bhagat NK \\ Indus University, India
}

Correspondence: Bhagat NK, Indus University, India, Email nirmanbhagat@gmail.com

Received: September 04, 2017 | Published: November 10, 2017

\section{Introduction}

Most Hydrologists try to find better model simulation of stream flow by using rainfall-runoff co-relationship. One of the most outstanding achievements of the last three decades is the development of rainfallrunoff co relationship, using which hydrologists can use rainfall data comprehensively to predict the discharge of river. ${ }^{1}$ The rainfallrunoff relationship in the early $19^{\text {th }}$ century was confined mostly to use of empirical formulae or the rational method to transform rainfall into surface runoff. For small scale problems the method based on time of concentration served the purpose but for larger catchments rational methods had to be modified. This method was seen as first basic rainfall runoff model. ${ }^{2}$ Reliable prediction of quantity and rate of runoff from land surface into streams and rivers is difficult and time consuming to obtain for un-gauged watersheds. However, this information is needed in dealing with many watershed development and management problems. ${ }^{2}$ Conventional models for prediction of river discharge require considerable hydrological and meteorological data. Collection of these data is expensive, time consuming and a difficult process. In this study, an attempt has been made to obtain a rainfall-runoff relationship for Lower Mahi Basin, India. Since the data collection is very expensive and time consuming, the rainfall data was collected only for the important rain gauge stations for a period of 10 years. Using the rainfall data, runoff depth was calculated using the SCS-CN (Soil Conservation Services-Curve Number) method. Observed rainfall and runoff was then co-related using regression equation. A simple regression of rainfall and runoff provides a means for estimating storm runoff when precipitation records are available. ${ }^{3}$

\section{Study area and data collection}

Mahi River is one of the major west flowing interstate river of India, draining into the Gulf of Khambhat. The Mahi basin is comprised of two sub-basins:- Mahi upper sub basin of $(65.11 \%$ of total basin area) consisting of 41 watersheds and Mahi lower sub basin (34.89\% of total basin area) consisting of 22 watersheds. It lies between $72015^{\text {"e }} 00^{\prime \prime} \mathrm{E}$ to $78015^{\circ e} 00$ " $\mathrm{E}$ and $220 \mathrm{~N}$ to $22040^{\text {ee }} 00^{\prime \prime} \mathrm{N}$ respectively. The basin map is shown in Figure 1. Only the lower Mahi Basin is considered for the present study. Figure 2 shows the rain gauging stations in the study area. As discussed in the previous sections, the data from only the key rain gauging stations was considered. Table 1 shows the details of the rain gauging station considered for the study the rainfall data is obtained from the rain gauging stations. To determine the runoff depth, SCS-CN method is used. For this, the weighted CN (Curve Number) of Lower Mahi Basin needs to be estimated. The same was estimated as 83.94. ${ }^{4}$ The basic equations for estimation runoff depth using SCS-CN method are as follows:

$$
\begin{aligned}
& S=\frac{25400}{C N}-254 \\
& Q=\frac{\left(P-I_{a}\right)^{2}}{P-I_{a}+S}
\end{aligned}
$$

Where, P: Precipitation (mm); Q: Runoff depth (mm) I : Initial Abstraction (0.2S).

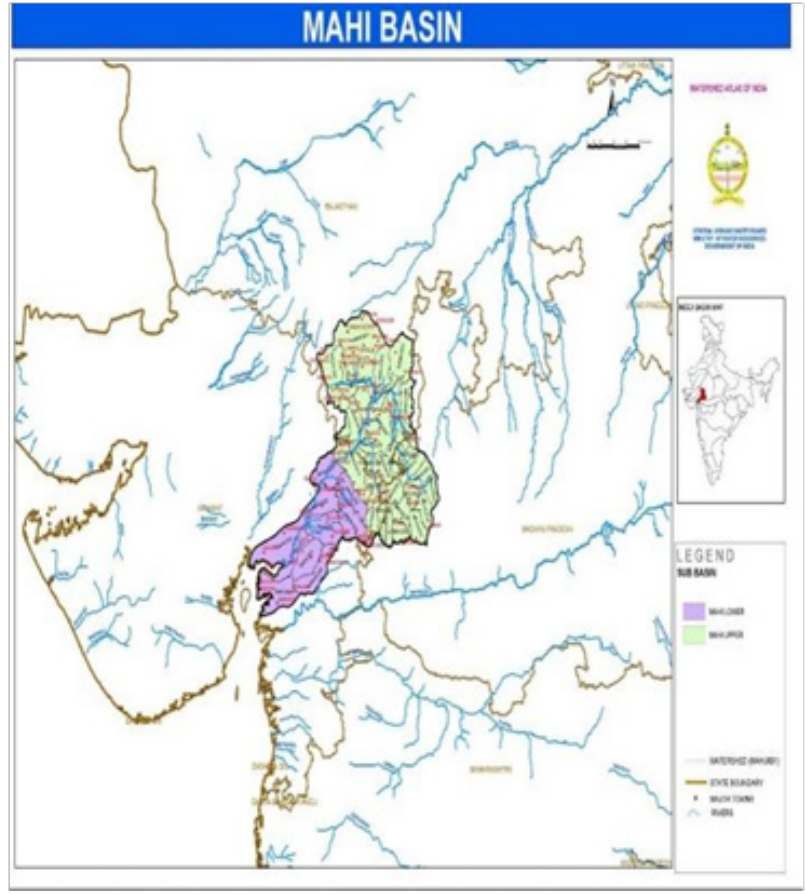

Figure I Mahi basin (Source: CGWB- Central Ground Water Board). 


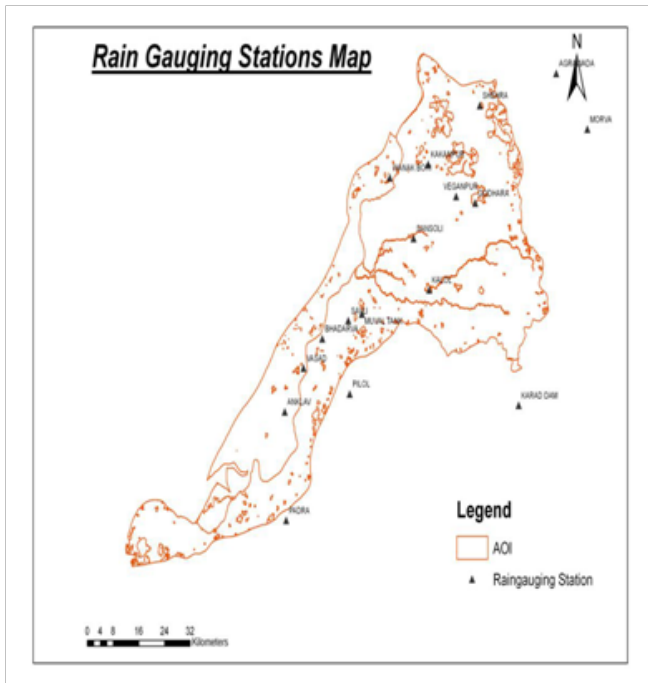

Figure 2 Rain gauging stations map (Source: India-WRIS Website).

Table I Details of rain-gauge stations

\begin{tabular}{|c|c|c|c|}
\hline Station & Latitude & Longitude & Ref. topo. sheet \\
\hline Anklav & $22022{ }^{\prime} 45^{\prime \prime}$ & 7300 I’35” & $46 \mathrm{F03}$ \\
\hline Bhadarva & $22030 ’ 57$ ' & 73008'29" & $46 \mathrm{FOI}$ \\
\hline Godhara & $22045^{\prime} 57^{\prime \prime}$ & 73036 '29" & 46F09 \\
\hline Kalol & $22036^{\prime} 15^{\prime \prime}$ & $73027 ' 58 ”$ & $46 \mathrm{F06}$ \\
\hline Sansoli & 22042’06” & $73025^{\prime} 13 ”$ & $46 \mathrm{F06}$ \\
\hline Shehra & 22056 '58" & 73037'29" & 46F09 \\
\hline Vasad & 22027'39"' & 73033'00" & $46 \mathrm{~F} 03$ \\
\hline
\end{tabular}

The runoff depth is obtained using the above equation using the total seasonal rainfall for any rain gauge station. Hence, a seasonal runoff depth is obtained. The rainfall-runoff co- relation is then obtained using the regression equation which is shown below: ${ }^{1-8}$

$$
r=\frac{N\left(\sum P R\right)-\left(\sum P\right)\left(\sum R\right)}{\sqrt{\left[\left(\sum P^{2}\right)-\left(\sum P\right)^{2}\right]\left[\left(\sum R^{2}\right)-\left(\sum R\right)^{2}\right]}}
$$

Where, P: Precipitation (mm); R: Runoff (mm)

As the value of " $r$ " reaches nearer to unity, the co-relation can be said to be a good one. Even though total runoff can be computed from total rainfall, the distribution of runoff cannot be assumed to be directly proportional to the distribution of rainfall. It is obvious that as rainfall continues and the ground becomes saturated, the percentage of rainfall which appears as runoff becomes larger and larger.

\section{Analysis and result}

Analysis of the data obtained from Godhara rain gauge station was carried out and results were obtained using eqn. (iii). The co relation " $\mathrm{r}$ " was calculated as 0.9958 which is almost nearer to unity. When the values were plotted in MS-Excel and regression analysis was carried out, the value of " $r$ " was obtained as 0.9997 . Figure 3 shows the result obtained from the graph plotted in MS-Excel. By comparing the result, it is evident that linear regression equation is giving a nearly accurate result for rainfall-runoff co-relation. Similarly, Figure 4Figure 9 shows the rainfall runoff co relation for the other rain gauges in the basin. The results are showing rainfall runoff co-relationship for all the important rain gauges in Lower Mahi Basin. The average value of the co-relation " $r$ " of all the stations is 0.9960 , which is almost near to unity. Also the rainfall runoff co-relationship for the entire lower Mahi basin was obtained using all the rainfall data available and the results are shown in Figure 10. The value of " $\mathrm{r}$ " for the entire basin was obtained as 0.9718 , also nearing to unity.

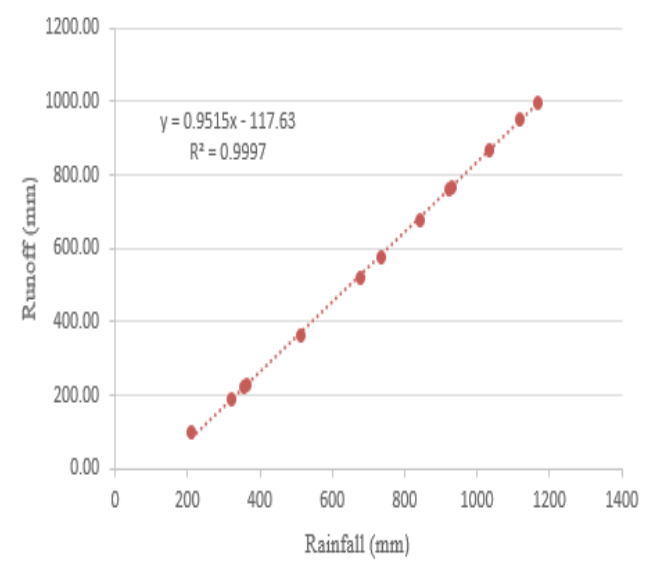

Figure 3 Rainfall runoff co relation for godhara rain gauging station.

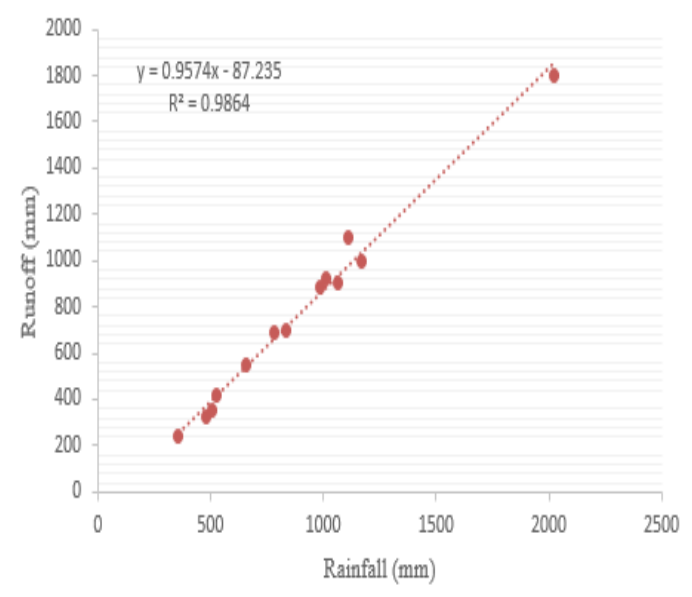

Figure 4 Rainfall runoff co relation for anklav rain gauging station.

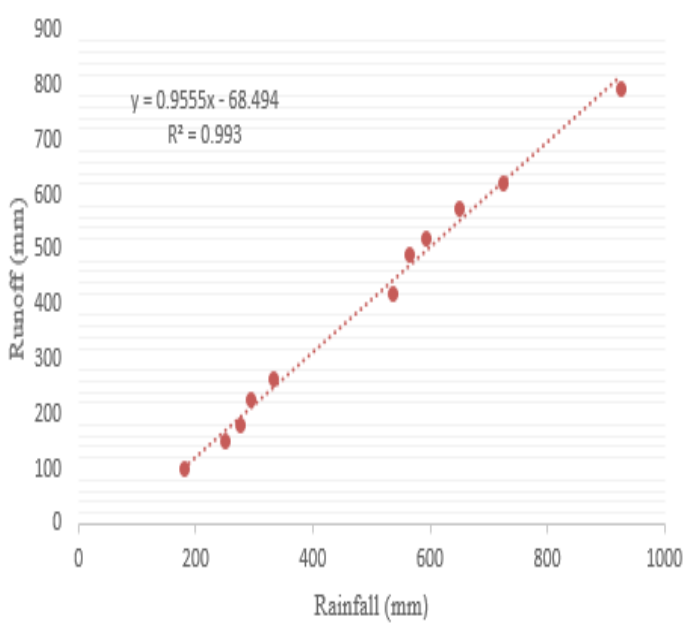

Figure 5 Rainfall runoff co relation for bhadarva rain gauging station. 


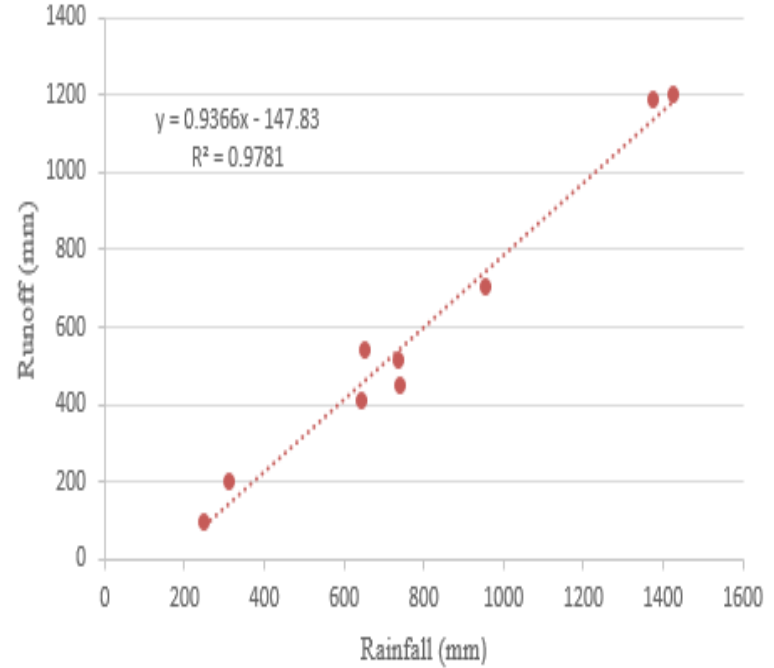

Figure 6 Rainfall runoff co relation for kalol rain gauging station.

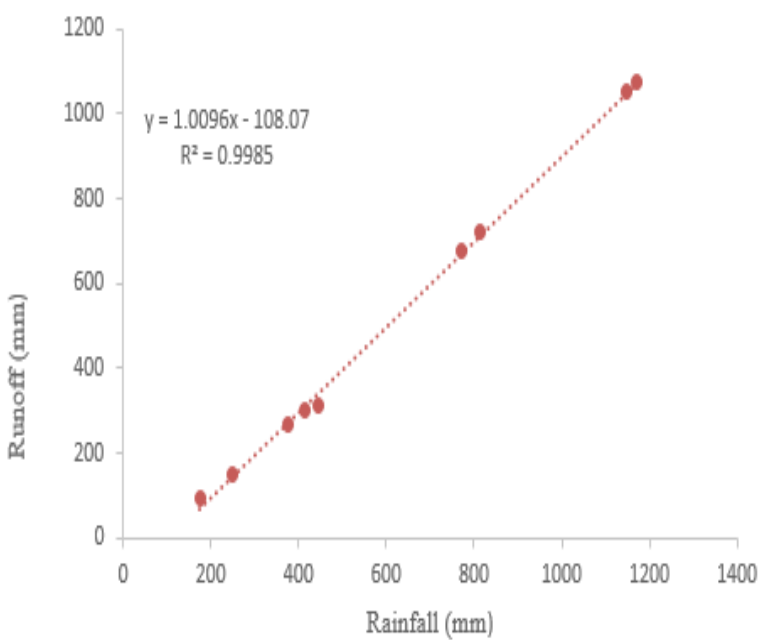

Figure 7 Rainfall runoff co relation for sansoli rain gauging station.

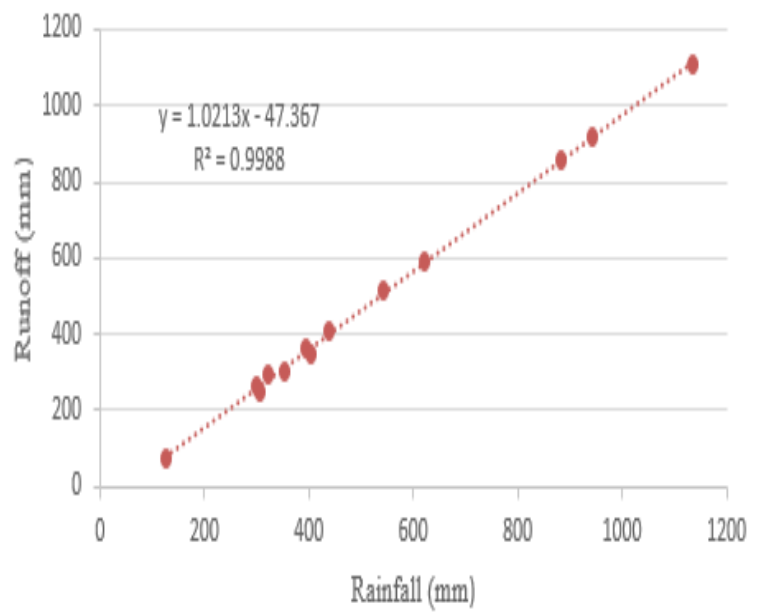

Figure 8 Rainfall runoff co relation for shehra rain gauging station.

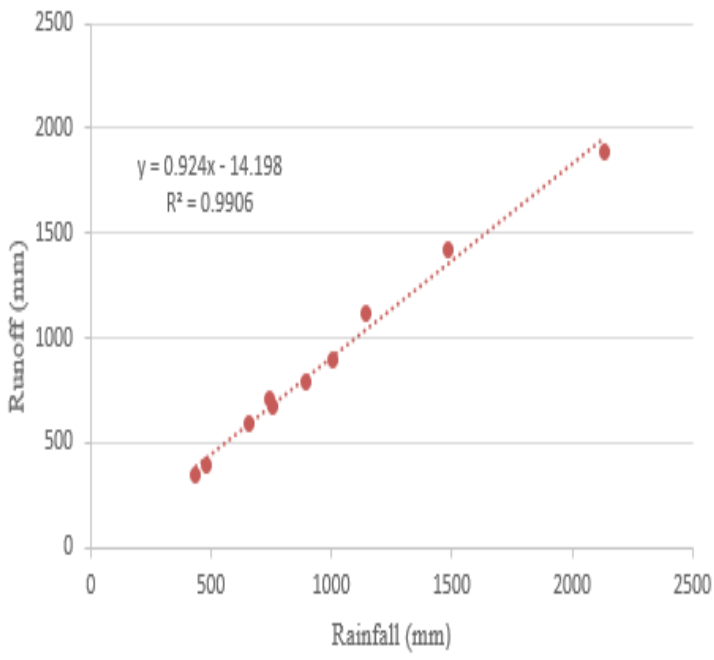

Figure 9 Rainfall runoff co relation for vasad rain gauging station.

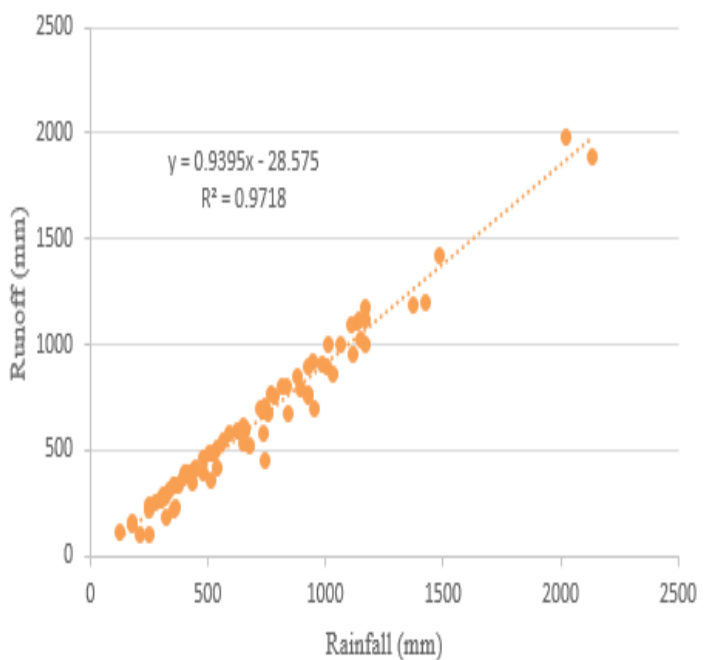

Figure 10 Rainfall runoff co relation for lower mahi basin.

\section{Conclusion}

This study has attempted to define a Rainfall-Runoff Corelationship for Lower Mahi Basin, India. Graphical regressions were made relating to storm rainfall, storm runoff was determined considering all the important catchment characteristics using the SCS-CN method. It was found that considerably good results were obtained by correlating rainfall versus runoff. The regressions were affected to some extent by the quality of the data from which they were derived. Runoff data was considered fairly well, as it does not take into account the infiltration in the catchment. The infiltration is the start of the event is different when the storm ends and this effects the runoff from the catchment. When the " $\mathrm{r} 2$ " value approaches to 1 , it means the river receives a regular rainfall every year and the flow is actually proportional to it. The co relation " $\mathrm{r}$ " for the basin is nearing the unity and such a correlation is said to be very good, which shows the catchment is more responsive to the rainfall it is receiving. The method presented in this study provides a tool for estimating runoff from a rainfall event. Improvements to the correlation can be made 
by varying the $\mathrm{CN}$-value and initial abstraction depending on the catchment characteristics per season. This tool will be useful in studies involving the computation of runoff hydrographs and corresponding frequencies.

\section{Acknowledgments}

None.

\section{Conflict of interest}

Authors declare there is no conflict of interest in publishing the article.

\section{References}

1. Subramanya K. Engineering Hydrology. Tata McGraw-Hill Publishing Company Limited, India; 2008. p. 1-434

2. Zhang GP, Savenije HHG. Rainfall-runoff modeling in a catchment with a complex groundwater flow system: application of the Representative Elementary Watershed (REW) approach. Hydrology and Earth System Sciences. 2005;9:243-261.
3. Askar M. Rainfall-runoff model using the SCS-CN method and geographic information systems: A case study of Gomal River watershed. WIT Transactions on Ecology and The Environment. 2014;178:1-12.

4. Bhagat NK. Estimation of SCS-CN for Lower Mahi Basin, Gujarat, India. International Journal of Advanced Engineering Research and Technology. 2016;4(4):1-3.

5. Harlan D, Wangsadipura M. Rainfall-Runoff Modeling of Citarum Hulu River Basin by Using GR4J. Proceedings of the World Congress on Engineering. 2010;2:1-5.

6. Meher J. Rainfall and Runoff Estimation Using Hydrological Models and Ann Techniques. National Institute Of Technology, India; 2014. p. $1-128$.

7. Amir MS, Khan MM, Mohammad Golam Rasul, et al. Automatic MultiObjective Calibration of a Rainfall Runoff Model for the Fitzroy Basin, Queensland, Australia. International Journal of Environmental Science and Development. 2013;4(3):1-5.

8. Quan NH. Rainfall-Runoff modeling in the Ungauged Can Le catchment, Saigon River Basin. Thesis Submitted to International Institute for GeoInformation Science and Earth Observation Enschede, Netherlands; 2006. p. $1-108$. 